\title{
Assessment of postoperative pain and foreign body sensation between two surgical methods coblator-assisted tonsillectomy versus conventional method
}

\author{
St. Konsulov', Sp. Konsulov², K. Dzhambazov³, P. Kopanov ${ }^{4}$ \\ 1 Medical University of Plovdiv, Department of Ear Nose and Throat disease, \\ University Hospital Kaspela, Plovdiv, Bulgaria \\ 2 Medical University of Plovdiv, Department of Ear Nose and \\ Throat disease St. George University Hospital, Plovdiv, Bulgaria \\ 3 University of Plovdiv Paisii Hilendarski, \\ Faculty of Mathematics and Informatics, Plovdiv, Bulgaria
}

\begin{abstract}
The tonsillectomy is one of the most common surgical procedure in the world. One of the commonest complications after the surgery are postoperative bleeding and postoperative pain. In relation with these complains and complications the patients have difficult recovery significant sensation of pain and foreign body sensation. The coblation -assisted tonsillectomy is fairly new surgical method and the focus is in the specific aspects of the surgical techniques and postoperative complications. In our prospective comparative study we include 60 patients divided equally: 30 surgically treated with the coblation method and 30 with conventional method. The average age of the participants is $6,87 \pm 3,01$ in the first group and $8,16 \pm 4,74$ in the second group. We compare the postoperative pain and the foreign body
\end{abstract}

\section{Introduction}

The extracapsular tonsillectomy is a surgical procedure where the surgeons dissecting tonsil from its surrounding fascia, so called „total“ or extracapsular tonsillectomy. In USA over 500000 tonsillectomy are performed annually. In Germany it is around 100000 cases per year. Postoperative pain is very common complain after the surgery. It is one of the most common complain which can delay the recovery process and patients especially children can't star eat and drink after the surgery. $(3,4,5,8,10)$.

\section{Coblator assisted tonsillecotmy}

The term "Coblation“ is derived from „Control Ablation“. This procedure involves non-heat driven process of soft tissue dissolution using bipolar radiofrequency energy under a conductive medium like normal saline. The method is pat- sensation in both groups. We measured the postoperative pain using Wong-Baker visual analogue scale with face images (0-no pain; $10-$ hurts worst). We measured the pain on the $1^{\text {st }}-2^{\text {nd }}$ and $7^{\text {th }}$ day after the surgery. We found statistically significant difference (p-value $<0.0005$ ) according to this parameter in both groups. In all of the three days after the surgery the pain is less intensive in the coblation group. Regarding the postoperative pain we found statistically significant differences between both methods in favor of coblatorassisted tonsillectomy (p-value- 0.0002).

Key words: tonsillectomy, coblator assisted tonsillectomy, postoperative pain, foreign body sensation.

ented in 1997 from Arthrocare. When current from radiofrequency probe pass through saline medium it breaks saline into sodium and chloride ions. These highly energized ions form a plasma field which is sufficiently strong to break organic molecular bonds within soft tissue causing its dissolution.

Blackburn and Ribble Valley Authority has owned the biggest database of coblator-assisted tonsillecotmy in UK and probably the biggest in the world approximately 850 operations. These data allow us to calculate the postoperative complications and to compare it with our results. The late hemorrhage $24 \mathrm{~h}$ after the surgery is due to infection of the tonsillar space. The contraction of pharyngeal muscles are responded for physiological cleaning in pharyngeal space. Postoperative pain is the commonest reason for difficult swallowing and lack of muscle contractions. This can lead to food retention, secondary infection and postoperative bleeding. The 
advantages of coblation assisted tonsillectomy are: lower level of pain after the surgery, low amount of blood loss intraoperatively, fast recovery and faster return to a normal diet. $(2,6,7,10)$

\section{Methods}

Our study is comparative prospective, involving 60 children in the age of 4-18y. The patients were divided into groups on equal basis according to the surgical technique - coblator assisted tonsillectomy versus conventional method. The children were included in the study after the consent form was sign by the Parents.

Including criteria: Paradise criteria for tonsillectomy (8)

Minimum frequency of sore throat episodes-7 or more episodes in the preceding year, OR

5 or more episodes in each of the preceding $2 \mathrm{y}$

3 or more episodes in each of the preceding $3 y$

Clinical features (sore throat plus the presence of one more qualifies episodes as a counting episode: Temperature $>38.3^{\circ} \mathrm{C}$, OR $101^{\circ} \mathrm{F}$

Cervical lymphadenopathy (tender lymph nodes or $>2 \mathrm{~cm}$ ), OR

Tonsillar exudate, OR

Positive culture for group A b-hemolytic streptococcus

* sore throat

* bad breath, which may related with cryptic tonsils

* enlarge and tender neck lymph nodes

* Hypertrophy- causing upper airway obstruction (obstructive sleep apnea)

Ever, dysphagia (trouble swallowing),sleep disorders, or cardiopulmonary

complication.

* Past history of Peritonsillar abscess

Excluding criteria: different age group

: very young age under 4

: presence acute infection

: refusal of surgery

: blood diseases

: unilateral tonsillar hypertrophy

: known blood disease

At the day of admission the patients were examined by ENT specialist and history was taken. On the same day the patients and parents have answered questions about any current acute diseases, any history of blood disease in the family, any known allergies, medication and opioid medication also current menstruation in older female patients. The venous blood was taken from the patients for full blood count and time of bleeding and coagulation. All the patients and parents were informed about the upcoming surgery, benefits and further complications. All of them sign a consent form before the surgery.

We measured the objective and subjective complains using Wong-Baker visual analogue pain scale (0-no hurt, 10 hurts worst).

Subjective complains:

Pain in swallowing (0-no hurt, 10 hurts worst). On the evening ward round the patients have asked about the pain using Wong-Baker visual analogue scale and notes has recorded in the patient history. The same questions was asked on the second day after the surgery.

- Foreign body sensation ( dysphagia or struggle in swallowing) yes/no

- Time when patient start eat and drink

- Objective

- Intraoperative bleeding

- Postoperative bleeding

- High temperature( fever)

- Dehydration

- Healing of postoperative wound

All the patients have stayed two nigh in the ward. After assessing the general condition and recovery of the patients they were discharged on the second day. All the patients visit the outpatient clinic 7 days after the surgery the pain and healing of the wound was assessed.

The statistical analysis was based on "criteria of sign" and was done by Wolfram Mathematic 11.

\section{Results}

We included 60 patients divided equally: 30-surgically treated with the coblation method and 30 with conventional method. The average age of the participants is $6,87 \pm 3,01$ in the first group and $8,16 \pm 4,74$ in the second group.

Regarding the postoperative pain in the $1^{\text {st }}$ day with the conventional method the average pain was measured 7,4 and SD- 0,93. On $2^{\text {nd }}$ day with the same method the average pain was 5,66 with SD 0,92 . On the $7^{\text {th }}$ day postoperatively it was 3,86 and SD 1,47. Regarding the postoperative pain in the $1^{\text {st }}$ day with the coblation method we measured average value 2,6 and $\mathrm{SD}-1,19$. On the $2^{\text {nd }}$ day with the same method average pain was 3,06 and 
SD 1,48 . On the $7^{\text {th }}$ day the average pain was 2,2 and SD was 1,27.

Chart 1. Average value of pain. Group-1 conventional method, Group-2 Coblator assisted tonsillectomy.

\begin{tabular}{|l|c|c|c|c|c|c|}
\hline & \multicolumn{2}{|c|}{$\begin{array}{c}\text { Pain 1-st } \\
\text { day }\end{array}$} & \multicolumn{2}{c|}{$\begin{array}{c}\text { Pain 2 } \\
\text { day }\end{array}$} & \multicolumn{2}{c|}{$\begin{array}{c}\text { Pain } 7^{\text {th }} \\
\text { day }\end{array}$} \\
\hline $\begin{array}{l}\text { Group1 } \\
\text { Group 2 }\end{array}$ & 1 & 2 & 1 & 2 & 1 & 2 \\
\hline Avarage & 7.4 & 2.6 & 5.66 & 3.06 & 3.86 & 2.2 \\
\hline SD & 0.93 & 1.19 & 0.92 & 1.48 & 1.47 & 1.27 \\
\hline Variance & 0.86 & 1.42 & 0.85 & 2.20 & 2.18 & 1.63 \\
\hline
\end{tabular}

Chart 2. Statistically significant difference regarding postoperative pain.

\begin{tabular}{|c|c|c|c|}
\hline $\begin{array}{c}\text { Pain 1-st } \\
\text { day_1 }\end{array}$ & $\begin{array}{c}\text { pain 2-nd } \\
\text { day }\end{array}$ & $\begin{array}{c}\text { Pain 7-th } \\
\text { day }\end{array}$ & $\begin{array}{c}\text { Foreign } \\
\text { body } \\
\text { sensation }\end{array}$ \\
\hline $\begin{array}{c}p \text {-value } \\
9.3132^{*} 10^{-10}\end{array}$ & $\begin{array}{c}p-\text { value } \\
7.4505^{*} 10^{-9}\end{array}$ & $\begin{array}{c}p-v a l u e \\
0.00006\end{array}$ & $\begin{array}{c}p \text {-value } \\
0.0002\end{array}$ \\
\hline
\end{tabular}

We found statistically significant difference between both methods regarding the postoperative pain and foreign body sensation on the $1^{\text {st }}$ day on the $2^{\text {nd }}$ day and $7^{\text {th }}$ day after the surgery. ( $p$-value $<0.0005$ ) (chart. 2, fig. 1, 2, 3, 4).

Regarding the postoperative pain and foreign body sensation on the $1^{\text {st }}$ and $2^{\text {nd }}$ day the values are too small which confirm that the results are based on both totally different surgical method.

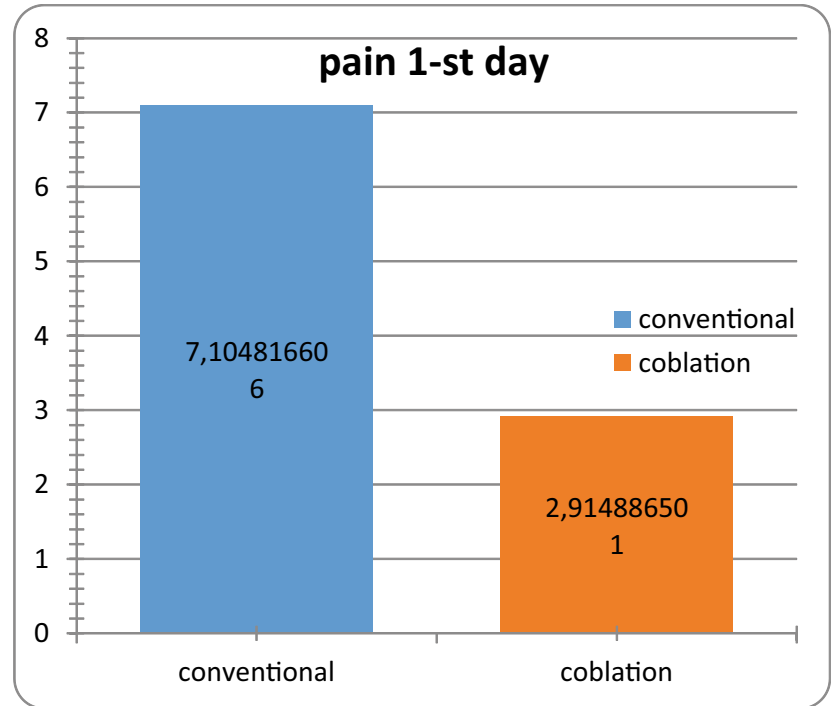

Fig. 1. Postoperative pain on the 1st day comparison between coblator-assisted tonsillectomy and conventional tonsillectomy.

The pain on the $1^{\text {st }}$ day postoperatively is significant weaker in the coblation method compare to conventional.

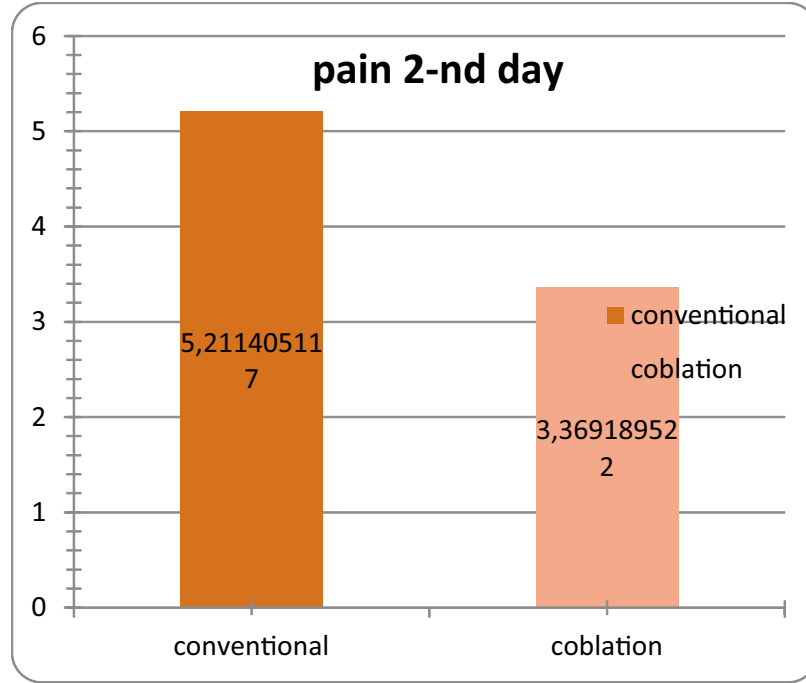

Fig. 2. Postoperative pain on the 2nd day comparison between coblator-assisted tonsillectomy and conventional tonsillectomy.

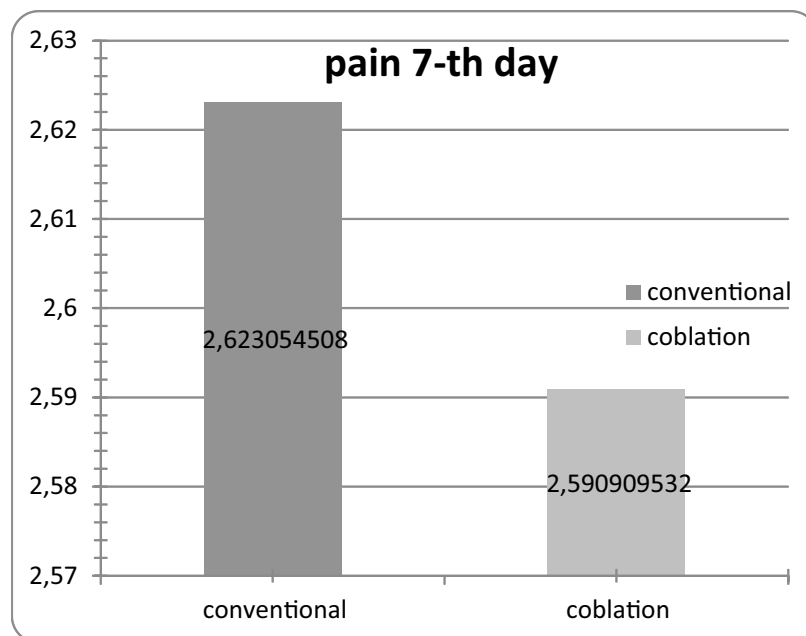

Fig. 3. Postoperative pain on the 7th day comparison between coblator-assisted tonsillectomy and conventional tonsillectomy.

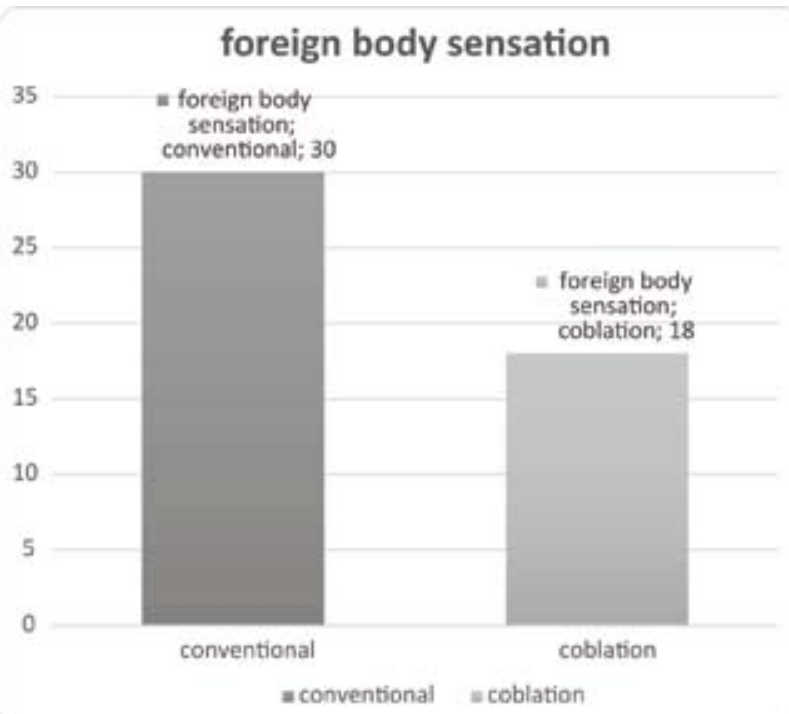

Fig. 4. Foreign body sensation-comparison between coblator-assisted tonsillectomy and conventional tonsillectomy. 


\section{Results analysis}

The tonsillectomy is one of most common surgical procedure in the world and may be the first surgery in the childhood. After tonsillectomy it can be seen different complain and complications. Some of this could be postoperative pain and foreign body sensation it can lead to struggling to eat and drink and delay recovery of the patients. $(1,5)$

In our study we found statistically significant lower level of pain in coblator-assisted tonsillectomy versus conventional method on the $1^{\text {st }}, 2^{\text {nd }}$ and $7^{\text {th }}$ day after the surgery.

The patients who was surgically treated with the coblation method have significant lower level of pain compare to conventional method. On the $1^{\text {st }}$ day it was average 4.8 points lower, on the second day it was average 2,6 point lower and on the $7^{\text {th }}$ day it was average 1,64 point lower. We assessed the pain using visual analogue pain scale of Wong-Baker. Our results confirm the results that we found in different studies and publications. In 2012 Wagner conducted the similar comparative study and has found significant lower intensity of pain using coblation method versus conventional. It was ( 0.90 versus 6.4 point). COBLATION process generates significantly lower temperatures $40-70^{\circ} \mathrm{C}$ on the contact tissue therefore minimizing damage to the surrounding healthy tissue. It is a possible reason for this big differences between both methods. (10)

In 2007 Matic and assistants conducted single-blind pilot randomized study type case-control. They include 80 patients in the age of 4-12y (16-60 kg). They compared two surgical method coblator-assist- ed tonsillectomy versus cold still dissection tonsillectomy with bipolar diathermy hemostasis (40/40). In 10 days after the surgery they assessed the postoperative pain, day of return to normal diet and healing of the wound. The groups were statistically comparative regarding the age, weight and surgical procedure. In regard of postoperative pain they haven't found statistically significant differences between them, but there is a tendency for weaker pain in the coblation method. They haven't found statistically significant differences regarding the postoperative pain, healing of the wound and foreign body sensation between both method rather than our study where we found statistically significant differences in the postoperative pain and foreign body sensation in favor of coblator-assisted tonsillectomy.

In 2007 and 2008 Mohammadreza conducted a double blind randomized study type case-control. The patients are divided on two groups regarding the surgical method coblator assisted tonsillectomy vs conventional tonsillectomy (47/47). They found statistically significant difference between both method regarding the postoperative pain in favor of coblation method $(p<0.01)[6]$.

\section{Conclusion}

In our study we found that coblator-assisted tonsillectomy is safer, more effective alternative method for tonsillectomy compare with conventional cold steel dissection tonsillectomy. The postoperative pain is weaker which leads to faster healing of postoperative wound and faster recovery of the patients.

\section{References}

1. Burton MJ, Doree C. Coblation versus other surgical techniques for tonsillectomy. Cochrane Database Syst Rev. 2007; 18(3): CD004619.

2. Haddow, K., M. L. Montague and S. S. Hussain (2006). „Post-tonsillectomy haemorrhage: a prospective, randomized, controlled clinical trial of cold dissection versus bipolar diathermy dissection." J Laryngol Otol 120(6): 450-4.

3. Hockenberry MJ, Wilson D, Winkelstein ML: Wong's Essentials of Pediatric Nursing, ed. 7, St. Louis, 2005, p. 1259.

4. Johnson LB, Elluru RG, Mayer III CM. Complication of adenotonsillectomy Laryngoscope 2002; 112: 35-37.

5. Kay DJ, Mehta V, Goldsmith AJ: Perioperative adeno-tonsillectomy management in children: Current practices. Laryngoscope 113: 592-597, 2003.

6. Mohammadreza O, Behrouz B, Navid O, Ahmad RO, Seyed A, Ghazizadeh H, Coblation versus traditional tonsillectomy: A double blind randomized controlled trial. J Res Med Sci. 2012 Jan; 17(1): 45-50.

7. Mitic S, Tvinnereim M, Lie E, Saltyte BJ. A pilot randomized controlled trial of coblation tonsillectomy versus dissection tonsillectomy with bipolar diathermy haemostasis. Clin Otolaryngol. 2007; 32(4): 261-7.

8. Paradise JL: Tonsillectomy and adenoidectomy. In Bluestone CD, Stool SE, Alper CM, et al (eds): Pediatric Otolaryngology 4th ed. Philadelphia, W. B Saunders: 1210-1222, 2002.

9. Temple RH, Timms MS. Paediatric coblation tonsillectomy. Int J Pediatr Otorhinolaryngol. 2001; 61(3):195-8.

10. Wagner J, Einfluss des Coblation ${ }^{\circledR}$-Verfahrens bei der Tonsillektomie auf die Häufigkeit von Nachblutungen und postoperativen Schmerzen, Dissertation zur Erlangung des Grades eines Doktors der Medizin der Medizinischen Fakultät der Heinrich-Heine-Universität Düsseldorf, Hals-Nasen-Ohren-Klinik der Heinrich-Heine-Universität Düsseldorf, Germany.

11. Milkov, M., I. Tsenev, D. Marev, Ts. Tonchev. Critical analysis of the bipolar radiofrequency thermotherapy as used for reduction of the soft palate and nasal turbinate in habitual snoring. - International Bulletin of Otorhinolaryngology - Varna, 4, 2008, No 1, 46-53.

12. Nedev, P., G. Boyadzhiev, M. Milkov. Types of interventions for the treatment of snoring and obstructive sleep apnea. International Bulletin of Otorhinolaryngology - Varna, 4, 2008, No 2, 47-51. 